\title{
MODEL KEWARTAWANAN YANG IDEAL UNTUK KONTEKS MALAYSIA - MENGIMBANGI ILMU KEWARTAWANAN BARAT DENGAN KEWARTAWANAN ISLAM ${ }^{1}$ \\ IDEAL JOURNALISM MODEL FOR THE MALAYSIAN CONTEXT - BALANCING WESTERN JOURNALISM WITH ISLAMIC JOURNALISM
}

\author{
Lee Kuok Tiung \\ Fakulti Sains Sosial \& Kemanusiaan, \\ Universiti Malaysia Sabah \\ lee@ums.edu.my \\ Siti Suriani Othman \\ Fakulti Kepimpinan dan Pengurusan, \\ Universiti Sains Islam Malaysia \\ suriani@usim.edu.my \\ Liana Mat Nayan, \\ Fakulti Industri Kreatif, \\ Universiti Tunku Abdul Rahman \\ liana@utar.edu.my
}

Tarikh dihantar: 5 Januari 2020 / Tarikh diterima: 20 Mac 2020

\begin{abstract}
Abstrak: Makalah ini bertujuan membincangkan sebuah rangka teoritikal berkaitan model kewartawanan yang ideal sesuai dengan konteks Malaysia yang unik sebagai sebuah negara sekular. Ini penting mengambilkira Malaysia sebagai sebuah negara membangun yang rakykatnya terdiri daripada masyarakat pluralistik yang berbilang kaum dan agama. Tiga tekanan paling besar yang terpaksa dihadapi kewartawanan di Malaysia ialah penularan fenomena globalisasi, kemunculan mendadak portal-portal berita alternatif menerusi Internet dalam mediaskap baharu Malaysia, dan hegemoni media Barat. Asas kepada perbincangan ini diambil daripada idea-idea model kewartawanan yang dikemukakan oleh sarjana-sarjana seperti Siebert et al. (1956), Rugh (1987), H.M. Tuah Iskandar (1990), Skjerdal (2008), Mowlana (1996), Elliot (2002), Eickelman dan Anderson (2003), Khiabany (2003), Mellor (2005), Berenger (2005), Seeram (2006), Iskandar (2007), dan beberapa lagi sarjana kewartawanan yang membincangkan tentang model kewartawanan. Premis model kewartawanan Barat pada asasnya berteraskan kepada kebebasan dan berorientasikan keuntungan manakala asas kepada kewartawanan Islam berpandukan kepada prinsip-prinsip Islam dan penekanan pandangan-pandangan Islam tentang peranan media seperti menyeru kepada kebaikan, membuat makruf, menghindar yang mungkar, dan seruan media menjadi muraqqib serta muhasabah kepada kerajaan. Melalui perbandingan kedua-dua model, analisis ini cuba mencadangkan sebuah model kewartawanan yang ideal sesuai dengan realiti konteks Malaysia yang penting mengambilkira pertimbangan meminimakan tekanan-tekanan pasaran, pihak yang berkepentingan, selain memastikan tiada mana-mana pihak dalam masyarakat pluralistik Malaysia yang dipinggirkan mahupun tertindas oleh apa yang disarankan.
\end{abstract}

Kata Kunci: model kewartawanan, demokrasi, masyarakat pluralistik, kebebasan bersuara, kebebasan akhbar, kewartawanan, penapisan kendiri.

Abstract: This paper aims to discuss a theoretical framework related to the ideal model of journalism in accordance with the unique Malaysian context as a secular country. This is important considering Malaysia as a developing country whose people consist of a pluralistic

\footnotetext{
${ }^{1}$ kertas ini telah dibentangkan dalam the International Conference on Social Sciences \& Humanities 2012 anjuran MENTION, Universiti Kebangsaan Malaysia pada 12-13 Disember 2012
} 
society of various races and religions. The three biggest pressures that journalism has to face in Malaysia are the spread of the phenomenon of globalization, the sudden emergence of alternative news portals via the Internet in Malaysia's new media, and the hegemony of the Western media. The basis for this discussion is taken from the ideas of the journalism model put forward by scholars such as Siebert et al. (1956), Rugh (1987), H.M. Tuah Iskandar (1990), Skjerdal (2008), Mowlana (1996), Elliot (2002), Eickelman and Anderson (2003), Khiabany (2003), Mellor (2005), Berenger (2005), Seeram (2006), Iskandar (2007), and several other journalism scholars discussing the model of journalism. The premise of the Western journalism model is basically based on the freedom and profit-oriented while the foundation of Islamic journalism is based on Islamic principles and the emphasis of Islamic views on the role of the media such as calling for good, doing good, avoiding evil, and the media call to muraqqib and reflection on the government. Through a comparison of the two models, this analysis attempts to propose an ideal journalism model in line with the realities of the Malaysian context which takes into consideration to minimize the market pressures, stakeholders, as well as ensuring that no party in Malaysian pluralistic society is marginalized or oppressed by what is suggested.

Keywords: model of journalism, democracy, pluralistic society, freedom of speech, freedom of the press, journalism, self-censorship.

\section{PENGENALAN}

Kewartawanan memainkan peranan penting dalam merealisasikan aspirasi Malaysia mencapai sebuah negara maju menjelang tahun 2020. Cabaran utama kepada amalan kewartawanan ialah mengekalkan perpaduan masyarakat majmuk yang mengamalkan kebudayaan dan kepercayaan agama yang berlainan sambil mengekalkan identitinya sebagai sebuah negara sekular. Dalam usaha kewartawanan mencorak hal ehwal masyarakat, wartawan dan editor terpaksa bergelut menghasilkan kandungan media yang sentiasa relevan kepada kehendak masyarakat. Proses menambah nilai terhadap isu-isu yang dilaporkan dipengaruhi oleh keunikan budaya, bahasa dan ideologi penerbit kandungan media yang berlainan malahan bertelagah sesama mereka untuk menegakkan kebenaran masing-masing. Ini terutamanya kecenderungan sudut berita yang berlainan membawa kepada pelbagai persepsi, penerimaan dan reaksi berbeza daripada masyarakat terhadap isu-isu yang disentuh.

Pihak akhbar juga harus sentiasa peka terhadap konteks yang lebih besar seperti memahami Islam merupakan agama rasmi persekutuan Malaysia dan etnik-etnik lain bebas mengamalkan kepercayaan masing-masing sepertimana termaktub dalam Perkara 3(1), Perlembagaan Persekutuan Malaysia dan rakyat Malaysia terikat dengan 'kontrak sosial' yang dipersetujui bersama semua etnik sewaktu menuju ke arah kemerdekaan Tanah Melayu (1957) dan kemudiannya pembentukan Malaysia (1963). Teori 'kontrak sosial' yang dipelapori oleh Hobbes, John Locke (1632-1704) dan Rousseau bertujuan memelihara hak rakyat sesebuah negara yang bersifat heterogen seperti masyarakat majmuk di Malaysia. Konsep kontrak sosial di Malaysia merujuk kepada persetujuan bersama yang dicapai di antara pemimpin-pemimpin yang mewakili kaum-kaum yang berbeza sewaktu proses menuntut kemerdekaan Persekutuan Tanah Melayu pada tahun 1957 dan seterusnya pembentukan Persekutuan Malaysia pada tahun 1963. Antara intipatinya termasuklah hak-hak istimewa Bumiputra, kewarganegaraan secara Jus Soli, dan kedudukan Raja-raja Melayu.

Perubahan mediaskap dipengaruhi oleh fenomena globalisasi dan perkembangan teknologi komunikasi telah menyaksikan ketembusan saluran-saluran media asing telah mewujudkan cabaran baharu kepada kewartawanan di Malaysia. Bagaimanakah kewartawanan di Malaysia menyesuaikan diri dalam pesaingan yang makin sengit dan transformasi kerajaan mengawalselia industri persuratkhabaran di Malaysia? Akhbar kini bukan sahaja terpaksa bersaing sesama saluran-saluran di dalam negara dan antarabangsa, mereka juga terpaksa 
bersaing dengan penyiar berita (newsbreakers) yang tidak terlatih melalui telefon pintar (smartphone) dan pada masa sama berwaspada memastikan operasi media mereka beroperasi mengikut konteks perundangan dan etika kewartawanan yang dibenarkan. Contoh himpun Bersih 2.0 yang telah muatnaik di facebook, Twitter dan YouTube dari lokasi sewaktu kejadian menunjukkan betapa berkuasanya media sosial yang telah menggalakkan kewartawanan warga (citizen journalism).

Khalayak di Malaysia lazimnya dengan mudah boleh menjumpai versi cerita berita yang berlainan dengan beberapa klik pada tetikus komputer atau sentuhan jari pada tetingkap skrinnya. Perbezaan tersebut merupakan sebab utama pelaporan berita yang berbeza-beza oleh akhbar yang berlainan meskipun sumber isu yang dirujuk adalah sama (apatah lagi berita antarabangsa). Akhbar tradisional berpegang kepada tiga peraturan utama (golden rules) iaitu dapatkan fakta, periksa transkrip dan rakaman anda untuk memastikan fakta betul, dan pastikan berada dalam lingkungan sempadan undang-undang negara. Steele (2011) dalam syarahannya yang bertajuk "Keadilan dan Kewartawanan: Islam dan Nilai-nilai Kewartawanan di Malaysia dan Indonesia" berhujah berita dan maklumat daripada media sosial bukanlah fakta kukuh yang disemak serta ditapis oleh editor berbanding amalan standard oleh media tradisional, kehadiran media sosial telah memberikan kesan ke atas kewartawanan akhbar cetak di Malaysia (New social media not true journalism - US academician. July 21, 2011, Thursday. The Borneo Post).

Etika profesion kewartawanan dalam konteks Malaysia seperti Kod Perilaku Profesional Angota Kesatuan Kebangsaan Wartawan Malaysia (NUJM) mahupun Kod Wartawan Malaysia pada dasarnya adalah sama dan terpakai untuk semua wartawan tetapi realiti yang boleh dilihat adalah pemberitaan yang dibuat oleh wartawan sering-kali adalah berbeza sehinggakan satu peristiwa yang sama mempunyai versi-versi cerita yang berlainan. Sering kali boleh menyaksikan media memainkan isu-isu sensitif yang mewujudkan keteganan kaum yang menjejaskan perpaduan negara melalui pembingkaian (framing) kandungan agama dengan politik mahupun provokasi-provokasi seperti dengan tajuk berita 'Apa lagi Cina Mahu?". Media di Malaysia telah beberapa kali menunjukkan kurang perihatin dan sensitiviti mereka dalam cara pelaporan berita seperti rakaman seorang wanita melakukan ketuk ketampi dalam keadaan bogel (tahun 2005), kontroversi penerbitan semula karikatur Nabi Muhammad S.A.W. oleh Sarawak Tribune yang diambil dari Jyllands-Posten sebuah akhbar Denmark (tahun 2006), pertikaian penggunaan kalimah Allah dengan membingkaikannya bersama-sama dengan isu pembakaran gereja dan kristianisasi (tahun 2010), dan sebagainya.

Begitupun terdapat juga kes-kes yang akhbar sebenarnya hanya melaporkan apa yang diperkatakan oleh pemimpin-pemimpin politik dan NGO yang merupakan penghinaan berbaur perkauman (contoh kes yang mengemparkan seluruh rakyat Malaysia adalah penahanan wartawan Sin Chew Daily, Tan Hoon Cheng di bawah ISA pada 2008) atau bertentangan dengan norma adat kebudayaan masyarakat Malaysia seperti agenda yang diperjuangkan menerusi Seksualiti Merdeka. Contoh-contoh isu-isu ini berupaya menyeramakkan kebencian sesama masyarakat apatah lagi rakyat Malaysia sepertimana menurut Shamsul Amri Baharuddin (2008) hidup dalam suasana 'stable tension.' Timbul juga persoalan di sini apakah ketegangan yang timbul tidak menjadi isu serius sekiranya media tidak melakukan pendedahan isu-isu tersebut kerana nyata insiden (peristiwa yang terjadi) yang dilaporkan media itu mencabuli hak asasi manusia (yang mana turut dilarang dalam ajaran Islam, Buddha, Hindu dan Kristian). Kita tidak boleh menganggap ia sebagai reaksi yang berlebihan (over re-acted) daripada segelintir masyarakat kerana dalam keadaan-keadaan tertentu seperti proklamasi darurat memerlukan kawalseliaan yang teliti ke atas media untuk mengawal ketenteraman awam.

Model kewartawanan yang boleh dilihat digunapakai di Malaysia pada masa kini kelihatan begitu pelbagai iaitu kombinasi unsur-unsur authoritarian (terutamanya pada akhbar arus perdana), liberalitarian (khasnya akhbar alternatif) dan juga teori tanggungjawab sosial 
(lahir daripada Suruhanjaya Hutchins). Meskipun kelihatan lebih cenderung kepada model kewartawanan Barat yang disebabkan ilmu kewartawanan yang pengamal-pengamal media di Malaysia perolehi adalah daripada model Barat di samping kurang model kewartawanan Islam yang boleh dijadikan rujukan. Globalisasi bukan sahaja menyaksikan ketembusan saluransaluan media ke dalam mediaskap Malaysia tetapi penularan ideologi-ideologi kebebasan akhbar mengikut konteks Barat yang dipelapori oleh kumpulan-kumpulan Badan Bukan Kerajaan (NGO). Keadaan ini turut menyebabkan wartawan yang terpengaruh dengan ideologi tersebut akan berusaha menyebarkannya dalam kandungan media yang mereka hasilkan manakala masyarakat dengan kecanggihan peralatan (gadgets) telekomunikasi bersama-sama perkhidmatan internet mengakses kepada saluran-saluran yang boleh memenuhi keperluan penggunaan media mereka.

Tidak lupa juga bahawa media dipengaruhi oleh pelbagai aspek politik, sistem perundangan, dan pasaran yang masing-masing mempunyai keistimewaan tersendiri. McQuail (2012) telah mengutarakan dua polemik berhubung hubungan di antara media dan masyarakat dalam konteks kontemporari iaitu pertamanya, media secara meluas dipercayai merupakan merupakan pemain utama menyeru kepada kebaikan mahupun keburukan dalam masyarakat. Kedua, media sedang melalui perubahan mendadak yang besar khususnya disebabkan oleh teknologi baharu dengan kesan kerangka perundangan dan kawalan sosial menjadi tidak relevan. Kedua-dua persoalan yang berkaitan dengan aspek sosial-budaya dan politik tersebut amat bertepatan dengan situasi yang dihadapi di Malaysia di mana wujud dua set perundangan yang mengawalselia saluran-saluran komunikasi yang ada iaitu peraturan yang ketat untuk media tradisional tetapi jaminan kebebasan sepenuhnya tanpa sebarang sekatan untuk media baharu (internet) melalui MSC Malaysia Bill of Guarantees (BoGs).

Komitmen daripada kerajaan Malaysia sehingga membawa kepada pengenalan Akta Perlindungan Pemberi Maklumat 2010 (Akta 711) [Whistleblower Protection Act 2010] sebagai sebahagian daripada usaha anti-rasuah di bawah program transformasi kerajaan secara tidak langsung juga akan memberi ruang yang lebih luas kepada kebebasan berakhbar. Akta 711 tersebut bukan sahaja melindungi (seperti kerahsiaan identiti) pemberi maklumat (whistleblower) tetapi juga menjanjikan insentif dan ganjaran sebahagian peratusan wang ganti rugi yang diperolehi semula oleh kerajaan.

\section{OBJEKTIF}

Persoalan utama makalah ini adalah untuk meneroka sama ada model kewartawanan Islam boleh mengantikan pelaporan yang bersifat propaganda (propagandist) dan bias satu dimensi (one-dimensional) mengikut demokrasi Barat. Ini berikutan model kewartawanan yang digunapakai di Malaysia cenderung kelihatan sebagai salah satu daripada 'bandwagonism' yang mengikut 'kemodenan' dan 'tamadun' Barat. Kebebasan akhbar (freedom of the press) Barat adalah berteraskan kepada konsep kebebasan (liberty) mutlak melainkan fitnah. Bolehkah kita memecahkan utopia model kewartawanan Barat dengan menggunakan nilainilai Islam untuk memperkukuhkan model kewartawanan di Malaysia? Atau intipati kontrak sosial itu sebenarnya yang menjadi 'penghalang' sebenar selama ini? Sama ada terdapat sebarang peluang (real chance) untuk sebuah model kewartawanan Islam yang kritikal dan bebas merupakan cabaran utama (dalam penulisan makalah ini). Justeru itu, matlamat utama kerja kerja ini adalah mengenalpasti beberapa prinsip asas model kewartawanan berdasarkan model kewartawanan Barat dan model kewartawan Islam yang sesuai. Nilai-nilai asas Islam dan garis panduan umum (dasar dan amalan) Islam yang cuba diketengahkan di sini adalah berdasarkan 'demokrasi Islam' yakni lari (keluar) daripada persepsi sempit berkenaan sebuah kerajaan totalitarian Islam yang gagal toleransi dengan rakyatnya yang bukan Muslim. Ini termasuk mengambilkira pergerakan pro-demokrasi dengan meneroka cabaran-cabaran umum 
yang dihadapi oleh stesen-stesen media dalam konteks mediaskap baharu yang cenderung kepada media baharu. Usaha ini dilihat penting untuk menjelaskan peranan wartawan professional yang lebih sesuai berbanding amalan kewartawanan yang terikat dengan akhbar yang berorientasikan keetnikan dan ideologi yang berbeza-beza.

\section{MODEL KEWARTAWANAN}

Usaha untuk memberikan gambaran holistik model-model kewartawanan yang wujud penting. Meskipun model kewartawanan Barat dilihat berbeza dengan nilai-nilai yang diketengahkan oleh kewartawanan Islam, masih terdapat persamaan-persamaan yang boleh dijumpai di antara kedua-duanya. Lebih banyak literatur ilmiah mengenai amalan dan teori-teori kewartawanan Barat boleh dijumpai disebabkan kajian-kajian amalan kewartawanan yang telah dilakukan oleh sarjana-sarjana di Barat berbanding hujah-hujah mengenai model kewartawanan Islam mahupun komunikasi Islam yang masih menjurus di peringkat perbincangan epistemologi dan ontologinya. Sungguhpun televisyen Al-Jazeera dari Qatar dan Al-Hijrah (Malaysia) memperuntukkan masa dan waktu siarannya untuk mengetengahkan kandungan yang berteraskan Islam dan Muslim, masih memerlukan kajian untuk mengesahkan sama ada ia berteraskan model komunikasi Islam. Berbeza dalam konteks negara-negara Barat yang telah mempunyai tradisi yang begitu lama yang mula dibincangkan oleh sarjana-sarjana seperti Lasswell (1948), Schramm dan Roberts (1971), Lazarsfeld dan Merton (1948), Siebert, Peterson, dan Schramm (1963) dan ramai lagi.

Dalam usaha menjelaskan motivasi seseorang wartawan (model kewartawanan) yang kompleks ini penting mengenalpasti model akhbar dan komunikasi yang beroperasi di negaranegara Islam moden. Cabaran utama adalah tiada satu model kewartawanan Islam yang tunggal boleh ditemui dalam kalangan kesemua 56 buah negara yang menganggotai Pertubuhan Persidangan Islam (OIC). Kebebasan akhbar untuk hampir setiap negara anggota tersebut berbeza (mempunyai keunikan tersendiri) daripada aspek sekatan, penapisan, pertimbangan moral, mahupun apabila menyentuh tentang media terikat dengan parti politik. Semua sistem kerajaan sama ada empayar, republik atau persekutuan mempunyai keunikan tersendiri dan pelbagai kerana misalannya sistem mornarki atau sistem pemerintahan beraja seperti Arab Saudi, Thailand, Brunei, England, Sepanyol, Malaysia sendiri dan sebagainya telah menyaksikan pelbagai jenis sistem media wujud.

\section{KEWARTAWANAN BARAT}

Premis utama model kewartawanan Barat adalah berteraskan kepada kebebasan dan berorientasikan keuntungan selaras dengan ideologi kapitalisme Laissez-faire. Permulaan kepada kebebasan akhbar pada hari ini dipercayai bertitik-tolak Peristiharaan Hak-hak Manusia sewaktu Revolusi Perancis (France Revolution) pada 1789 iaitu berasaskan kepada kebebasan mengikut konsep demokrasi Barat yang dimulakan di Yunani. Banyak juga idea-idea disumbang oleh pemikir-pemikir politik seperti Thomas Hobbes (1588-1679), John Milton yang merupakan pencetus idea kebebasan akhbar [yang terkenal dengan karyanya Areopagitica (1644)], John Locke (1632-1704) yang melahirkan idea teori akhbar libertarian, Jean Jacques Rousseau (1712-1778) dan John Stuart Mill (1806-1973). Petikan penting daripada John Stuart Mill yang sering dirujuk sehingga masa kini ialah kenyataan seseorang itu harus diuji kesahihannya termasuk mendapatkan pandangan daripada pihak yang bertentangan untuk mengetahui kebenarannya.

Liberasi media Barat juga menyaksikan negara seperti Perancis, dan Denmark mempunyai tradisi seronok mempermainkan (poking fun) agama, adat tradisi kebudayaan dan pemimpin politik mereka dari dahulu lagi. Penerbitan yang bercorak lucah juga dibenarkan di bawah teori libertarian. Islam dan Muslim hanyalah sasaran baharu mereka kerana agama Kristian dan adat kebudayaan mereka telah menjadi bahan gurauan mereka sehinggakan sudah 
banyak literasi jenaka Yahudi mengikut tradisi-tradisi yang berlainan boleh dijumpai. Hak kebebasan bersuara yang dijamin dalam perlembagaan persekutuan Amerika Syarikat membolehkan mereka bersuara apa-apa sahaja tanpa kira betapa ia 'menyinggung' ('offensive') orang lain kerana salah satu justifikasi prinsip utama mereka adalah "you don't have the right to not be offended." Atas dasar itulah sebahagian saluran media di Barat mempersendakan Islam, Muslim dan Nabi Muhammad S.A.W. Prejudis terhadap Islam dan Muslim telah melahirkan fenomena yang dikenali sebagai Islamofobia. Bagi mereka hanya hasutan (incitement) yang menjurus kepada keganasan harus ditapis dan fitnah (defamation) yang yang mencabuli privasi memberikan hak kepada individu yang menjadi mangsa mengambil tindakan perundangan untuk dapatkan keadilan. Usaha-usaha yang dimulakan oleh organisasi-organisasi yang berteraskan agama Islam dan Muslim untuk melarang menggunakan ungkapan yang akan menyemarakkan diskriminasi, ekstremisme dan salah faham yang membawa kepada polarisasi dan perpecahan masyarakat di Amerika Syarikat baru-baru ini pula ditentang hebat oleh kumpulan-kumpulan hak asasi manusia (contoh anti-blasphemy).

Kebebasan merupakan kata kunci utama di dalam model kewartawanan Barat tetapi ramai yang terlepas pandang kebebasan yang dimaksudkan itu bukanlah kebebasan mutlak yang tidak bertanggungjawab. Realitinya kebebasan akhbar di Barat tidaklah sebebas yang diwar-warkan terutama mereka sendiri turut mempunyai perundangan yang menyerupai Akta Keselamatan Dalam Negeri 1960 (ISA) di Malaysia untuk mengawalselia pengaliran maklumat. Mereka juga mempunyai undang-undang yang melindungi maklumat-maklumat tertentu kerajaan sebagai sensitif atau diklasifikasikan sebagai rahsia atas dasar kepentingan nasional sepertimana Akta Rahsia Rasmi 1972 (OSA) di Malaysia.

\section{KEWARTAWANAN ISLAM}

Kewartawanan dalam Bahasa Arab sahafah merupakan suatu profesion yang diiktiraf dalam Islam. Meskipun perbincangan tentang model kewartawanan Islam masih terbatas, hakikatnya telah ada wacana tentang rupa bentuk dan elemen-elemen yang harus ada dalam kewartawanan Islam. Umumnya, kewartawan Islam menyeru kepada amalan kewartawanan yang mempromosikan kebaikan publik (public good) dan keseimbangan yang turut sama ditemui dalam model kewartawanan Barat. Segi literasi pengkonsepannya, berita sememangnya bukanlah sesuatu yang asing dalam ajaran Islam. Al-Quran menggunakan perkataan naba' lebih daripada 40 tempat yang merujuk kepada Allah yang menjadi sumber utama berita yang diwahyukan. Kebebasan bersuara dalam Islam telah lama mendapat pengiktirafan daripada pemimpin-pemimpin seperti Kalifah Umar Al-Khattab (Khulafa' ar-Rasyidin) dan al-Hashimi (Khulafa' Abbasiyah). Sejarah Tamadun Islam menunjukkan kewujudan sistem politik yang berbeza-beza dalam Dunia Islam dari zaman kerajaan Madinah kepada Umayyah (661-750), kerajaan Abbasiyah (750-1258) ke era moden dan beberapa kerajaan besar yang diperintah oleh Sultan seperti kerajaan Uthmaniyyah (1281-1924), Safavid (1501-1722) dan empayar Mughal (1526-1857). Rugh (1987) pernah memperhalusi empat teori akhbar klasik Siebert, Peterson dan Schramm (1963) untuk disesuaikan dengan ciri-ciri media Arab berdasarkan kepada lapan belas negara-negara Arab menyimpulkan beberapa jenis media iaitu media mudah alih (mobile), media loyalis atau setia (seperti Iraq di bawah Saddam Hussein), media yang pelbagai (seperti Lubnan pada 2002) dan media peralihan. Kajian lanjut daripada Skjerdal (2008) juga merumuskan dapatan yang sama.

Konsep-konsep dalam Islam yang menegaskan demokrasi khususnya Syura (perundingan bersama), Ijtihad (penilaian interpreatif yang mandiri), Bai'ah (sumpah taat setia), (kepimpinan), Ijma (kesepakatan masyarakat), Maslahah (kepentingan awam), dan Ahl al-hall wa al- 'aqd (ahli-ahli syura). Sarjana seperti Hamid Mowlana (1996) pula menekankan konsep Tauhid (توحيد) dalam penghujahan mengenai kebebasan akhbar dalam perspektif Islam. Tauhid merupakan asas kepada akidah (sistem moral Islam) Muslim yang menegaskan 
penyatuan dengan Tuhan yang satu dan Maha Esa. Kebebasan bersuara seperti mana menurut Mawdudi (1976), Nasr (1980), dan Mohammad Hashim Kamali (1997) merupakan salah satu hak yang diiktiraf oleh Islam (Nerawi, 2012). Memetik kata-kata Mawdudi (1976: 29), "hak kepada kebebasan bersuara penting untuk menggalakkan kebaikan dan kebenaran bukan sahaja suatu hak dalam Islam tetapi merupakan suatu obligasi”. Kod etika kewartawanan Islam menekankan hukum syariat iaitu pengetahuan tentang halal dan haram. Prinsip kebebasan bersuara dalam Islam menurut Mohammad Hashim Kamali (1997) adalah menyeru kepada kebaikan dan melarang kejahatan (Hisbah), nasihat yang ikhlas (Nasihah), penaakulan peribadi (Ijtihad), kebebasan untuk mengkritik (Hurriyayat al-Mu'aradah), dan kebebasan untuk meluahkan pendapat (Hurriyyat al-Ra'y).

Memetik daripada penulisan Zulkiple Abd. Ghani (2001), sarjana Sayeed Al-Seini (1986: 228) meringkaskan konsep berita dalam Islam dengan larangan terhadap menyebarkan berita palsu dan yang bertujuan daripada merosakkan kehidupan masyarakat (Surah al-Hujurat 49:15; Surah an-Nur 24:19). pengalaman daripada usaha pengumpulan, penapisan dan penyebaran hadis oleh ulama-ulama hadis menjadi sumber rujukan penting untuk mengendalikan berita dalam Islam (Zulkiple Abd. Ghani, 2001:10). Nerawi (2012) merumuskan kebebasan bersuara dalam Islam menyeru kepada kebaikan dan melarang salah laku, menegakkan kebenaran, mengutamakan ajaran Tuhan dan mematuhi adab Islam. Kebaikan penapisan kendiri, akauntabiliti, membawa faedah dan bukannya kemusanahan, dan menjaga kemuliaan diri. Sarjana-sarjana lain yang turut banyak membincangkan tentang aspek ini ialah Eickelman dan Anderson $(1997,2003)$

\section{KONSEP KEBEBASAN BERSUARA \& KEBEBASAN AKHBAR: PENAPISAN KENDIRI DARI PERSPEKTIF ISLAM DAN BARAT}

Kebebasan akhbar dan kebebasan bersuara mempunyai makna yang amat berbeza dalam konteks budaya dan politik yang berlainan di bawah skop kedaulatan undang-undang yang merupakan penentu demokrasi sesebuah negara. Kedua-dua jenis kebebasan ini sebenarnya bergantung kepada sejauhmana demokrasi sesebuah negara memberi ruang kepadanya. Teras permasalahan yang utama ialah dilema mencari titik seimbangan antara kebebasan media dengan kepentingan publik kerana mencari kesepadanan (persamaan) di antara prinsip-prinsip kewartawanan Barat dengan prinsip-prinsip kewartawanan Islam lebih mudah dilakukan. Cara mana akhbar menggambarkan sesuatu peristiwa yang sama dan apakah nilai-nilai tambah yang dimasukkan oleh wartawan ke dalam sesuatu peristiwa yang dilaporkan untuk membantu khalayak menginterpretasi sesuatu isu sering kali mengundang perdebatan. Kewartawanan interpretatif sebergini merupakan sesuatu yang salah kerana menghakimi sesuatu kes yang baharu dibawa ke muka keadilan seolah-olah defendan sudah disabitkan bersalah oleh mahkamah malah ada yang baharu ditangkap dan belum sempat dibicarakan.

Sebalik perbezaan antara kewartawanan Barat dengan kewartawanan Islam, keduaduanya berkongsi banyak persamaan tentang apa itu kewartawaan yang baik dan sebaliknya. Ini terutamanya dalam aspek objektiviti, kebenaran, menghormati hak privasi, dan larangan mensensasikan sesuatu peristiwa untuk meningkatkan jualan akhbar semuanya boleh dijadikan asas kepada mencari sebuah model profesionalisme kewartawanan yang universal. Objektiviti dalam kajian Das'ad Latif, Fauziah Ahmad, dan Normah Mustaffa (2016) mengambil huraian daripada teori Westershal yang mempunyai penjelasan yang mudah difahami iaitu menepati fakta (factuality) dan tidak berat sebelah (impartiality). Kebebasan bersuara telah diiktiraf sebagai hak asasi manusia di peringkat nasional dan antarabangsa. Kebebasan bersuara merangkumi usaha mencari, menerima dan menyebarkan maklumat ada tertera di dalam Perkara 19, Perisytiharaan Hak Asasi Manusia Sejagat (Universal Declaration of Human Rights - UDHR) dan maksud hak yang sama turut termaktub pada Perkara 10, Perlembagaan Persekutuan Malaysia. Begitupun, tidak kira sama ada di England, Amerika Syarikat, Perancis 
dan sebagainya, hak ini sebenarnya bukanlah hak mutlak kerana terdapat sub-seksyen dalam perundangan yang sama menyatakan had kebebasan tersebut khususnya bila mana melangkaui batas kebebasan individu lain. Akta Patriot di Amerika Syarikat, Akta Anti-terrorisme di United Kingdom, Akta Anti-keganasan 2001 di Kanada, dan Akta Anti-keganasan 2005 di Australia pada hakikatnya menyerupai ISA yang baharu dimansuhkan di Malaysia.

Masyarakat sivil di dunia Barat kelihatan bergelut untuk memahami dunia Islam dan Muslim berdasarkan reaksi sebahagian besar pengamal atau professional media yang prejudis Islam dan Muslim. Sarjana seperti Esposito (1992) dalam diskusi Islamofobia misalannya menjelaskan Barat mendapati lebih mudah untuk memusnahkan (demonizei) Islam dan Muslim daripada cuba memahaminya. Ia boleh jadi sesuatu yang disengajakan berikutan keengganan mereka untuk cuba memahami kerana mendapati lebih mudah mengkritik daripada berusaha untuk memahami Islam dan Muslim. Dalam konteks Barat-Islam, layanan yang tidak seimbang dan tidak adil (sering diputarbelitkan). Laporan yang tidak adil terhadap isu-isu di Timur Tengah dan negara-negara Islam oleh media Barat merupakan perkara biasa (Hafez 2000). Media nasional di Malaysia boleh dilihat fokus pada corak propaganda anti-Israel dan isu-isu (konflik senjata di Iraq dan Afgahnistan, malah Arab Springs dipotret sebagai imperialisme Barat. Sepersoalan yang harus diperdebatkan di sini adalah apakah pola pelaporan media di Malaysia semata-mata didorong oleh reaksi kewartawanan di dunia Islam terhadap liputan berita yang negatif, dan stereotaip terhadap Islam dan Muslim oleh media Barat (seperti menerusi Islamofobia). implikasi kod kewartawanan Barat mahupun Islam yang berbeza dapat dilihat pada komunikasi silang-budaya dan antarabangsa.

Hamid Mowlana (1996) yang memperkenalkan model komunikasi Islam (Model 'Alternatif' Mawlana) berhujah bahawa negara-negara Barat adalah kerajaan yang berasaskan prinsip-prinsip individual manakala kerajaan-kerajaan Islam adalah berteraskan masyarakat yang berpegang kuat kepada agama berpandukan kepada peraturan dan ajaran Al-Quran dan As-Sunnah (juga merupakan Perlembagaan paling utama dalam Islam) - menekankan budaya toleransi berpandukan hormat menghormati dan kasih saying. Kita peru terima hakikat di Dunia ini ada ada bermacam jenis Negara dengan sistem pentadbiran yang berlainan. Persekutuan Malaysia bukannya sebuah Negara Islam tetapi merupakan anggota OIC. Majoriti rakyatnya pada ketika ini ialah Bumiputera Islam tetapi dalam Perlembagaan Persekutuan menjamin kebebasan beragama meskipun adakalanya nampak jelas berlaku proses Islamisasi. Brunei Darussalam yang terletak di Kepulauan Borneo merupakan sebuah Negara Islam yang diperintah berdasarkan sistem monarki. Indonesia merupakan sebuah republik yang mempunyai jumlah penduduk Islam terbesar di Dunia tetapi Republik China mempunyai sejarah ketamadunan Islam yang lebih panjang daripadanya.

\section{PERBINCANGAN}

Kebebasan bersuara di Malaysia harus difahami dan diamalkan dalam sempadan perundangan dan toleransi kebudayaan masyarakat majmuk. Model kewartawanan Islam dengan mengkombinasikan ilmu-ilmu dan nilai-nilai yang sesuai daripada pelbagai sumber termasuk ilmu kewartawanan yang berproksikan kepada Barat bersama dengan nilai-nilai Islam. Ini juga bermakna kita terpaksa menolak penerapan nilai-nilai Islam secara kaffah iaitu sempurna dan menyeluruh ke dalam model kewartawanan yang ingin diperkenalkan. Usaha untuk menyetempatkan (localise) genre berita tidak semestinya akan mendapat sambutan disebabkan penularan nilai-nilai kebaratan dalam generasi baharu di Malaysia. Setiap generasi mempunyai perspektif dan keperihatinan yang unik dan juga cara pemikiran dan percakapan yang unik yang tertentu. Setiap generasi juga menanyakan persoalan-persoalan yang tidak pernah ditanya oleh generasi sebelumnya, dan mereka menanyakan soalan lama dalam cara yang baharu. Ini sangat berbeza dengan perubahan intelektual kerana timbul kemusykilan akhbar lebih cenderung memperdagangankan pengetahuan budaya. Bila masa seseorang itu mempunyai hak 
untuk tidak mengikut kerajaan? Bolehkan kerajaan melanggar peraturan moral sekiranya kebajikan negara memerlukannya (keadilan sosial)?

Apakah model kewartawanan Barat memfokus kepada hak individu sebaliknya kewartawanan Islam menekankan ajaran agama di mana ada kuasa yang lebih tinggi iaitu Allah? Asas kepada kewartawanan Islam adalah berpandukan kepada prinsip-prinsip Islam dan Muslim bersama-sama dengan penekanan pandangan-pandangan Islam tentang peranan media khususnya menyeru kepada kebaikan, [sifat Siddiq (benar), amanah, tabligh (menyampaikan), fatanah (kebijaksanaan)] membuat ma'ruf (prinsip al-amru bi al-ma 'ruf wa al-nahy 'an almunkar), menghindari diri daripada yang mungkar, dan seruan media menjadi muraqqib serta muhasabah yakni sebagai pemerhati (watchdog) kepada kerajaan. Sepintas lalu aspek-aspek yang ditekankan ini mempunyai persamaan dengan nilai-nilai yang ditekankan dalam kewartawanan Barat. Sememangnya senang untuk menyatakan seseorang wartawan mesti adil dan tidak melanggari undang-undang. Persoalannya ialah undang-undang siapa?

Menolak definisi kebebasan bersuara Barat adalah bersuara tanpa batas mahupun penapisan (censorship) tidak kira sama ada mencari, mendapatkan mahupun menyebarkan maklumat berdasarkan konsep kebebasan berfikir dan kebebasan menilai. Ini mendorong lahirnya asas 'seseorang tidak mempunyai hak untuk tidak disinggung' ('people do not have the right not to be offended"). Mudah sahaja sebabnya iaitu kerana setiap individu berhak meluahkan pandangan diri masing-masing dan mana-mana individu yang tidak berkongsi makna dengan mesej tersebut akan tersinggung. Timbal baliknya, individu tersebut juga tidak mempunyai hak menghalang dikritik oleh individu yang bercanggah pendapat dengannya, kecuali dibicara mengikut undang-undang Syariah.

Timbul persoalan di sini iaitu bagaimana dengan media bebas daripada politik? Idea Mohd Safar Hasim (1997) Malaysia harus mengamalkan bertanggungjawab di mana menolak konsep yang diamalkan di negara diktator atau bukan demokarsi dan juga kebebasan yang keterlaluan menyerupai peranan media dalam konteks Islam adalah bersesuaian dengan konteks al-maqasid al-syar 'iyyah, iaitu pendekatan dari sudut tanggungjawab sosial dan juga dari sudut pembangunan (Musa Abu Hasan \& Narimah Ismail 1998) Politik dan media. Perkara pokok kedua yang harus diambilkira ialah hubungan antara kuasa politik dengan kuasa media. Ini memerlukan suatu persefahaman bersama antara politik dan media berdasarkan kesedaran dan keinsafan untuk mengekalkan keharmonian antara penduduk Malaysia dan juga memacu mereka terus ke arah pemodenan negara khususnya Wawasan Kemakmuran Bersama 2030 (WKB 2030).

Falsafah negara yang boleh dilihat menerusi dasar dan polisi sama ada domestik dan luar negara. Media di Malaysia juga harus mendukung dasar, polisi dan aspirasi kerajaan untuk membawa negara menjadi sebuah negara maju dengan rakyatnya berpendapatan tinggi. Perkembangan teknologi, deregulasi dan peningkatan pengkomersilan telah bergabung menjadi ancaman kepada usaha mencari jalan untuk membawa media menuju ke arah yang mampu memenuhi keperluan masyarakat. Seringkali rakyat Malaysia kedengaran pertikaian serta sindiran-sindiran terhadap apa yang terencana di dalam Wawasan 2020, yang disusuli dengan Islam Hadhari, 1 Malaysia dan terbaharu WKB 2030. Pernah ada yang mendakwa ada lagi pelan perancangan yang lebih ideal dan holistik seperti Buku Jingga yang dianggap lebih praktikal dan menguntungkan tetapi kita harus sedar bahawa itu ialah disebabkan percanggahan ideologi politik antara parti-parti yang bersaing. Pokok pangkalnya pembangunan dan kemajuan ekonomi demi kesejahteraan rakyat yang kini bergelut dengan kos sara hidup yang makin hari makin meningkat. Media dalam konteks ini mempunyai peranan penting sebagai pengantara iaitu pendamai (peacebuilding) di antara rakyat dengan kerajaan.

Meskipun majoriti penduduk Malaysia ialah Muslim, Malaysia merupakan sebuah negara sekular, perundangan yang utama digunapakai adalah undang-undang sekular (common law) hasil kesinambungan daripada kerajaan pentadbiran British (yang memperkenalkan 
undang-undang British bermula di Pulau Pinang dan seterusnya seluruh Semenanjung selepas 1874) dan mengambilkira masyarakat pluralistik Malaysia. Sungguhpun Malaysia juga mempunyai undang-undang Syariah, konteks penggunaannya terbatas kepada masyarakat Muslim yang merujuk kepada 61.3 peratus rakyat Malaysia (Buddha 19.8\% dan Hindu 6.2\%) (sumber: Bancian Jabatan Perangkaan Malaysia, 2010). Kes-kes berkaitan perundangan komunikasi yang dibicarakan di Malaysia semuanya berteraskan kepada perundangan sekular khususnya Akta Hasutan 1948, Akta Fitnah 1957, Akta Mesin Cetak dan Penerbitan 1984, Akta Rahsia Rasmi 1972 dan Akta Keselamatan Dalam Negeri 1960 yang lebih sinonim dengan nama 'ISA'. Keadaan ini menimbulkan kesulitan kepada usaha mempromosikan perundangan komunikasi yang berteraskan ajaran Islam apatah lagi rakyat Malaysia pada masa kini begitu fobia bila mendengar tentang Hudud. Ini semestinya akan mempengaruhi persepsi dan penerimaan masyarakat terhadap sebarang usaha untuk mengangkat sebarang statut yang berasaskan nilai-nilai Islam di Malaysia buat masa ini. Pihak yang ingin mengadvokasi suatu perundangan yang sedemikian rupa juga akan menghadapi kesukaran memperolehi satu model kewartawanan Islam dari luar yang sesuai untuk diadaptasikan ke dalam konteks Malaysia terutama bila media di Malaysia diiktiraf sebagai sebuah model kepada negara-negara Islam yang lain. Sesetengah negara Islam yang mempunyai peratusan Muslim yang lebih tinggi sering dikecam disebabkan sistem pentadbiran kerajaan membiarkan berlaku diskriminasi kaum dan penafian hak orang lain. Situasi sedemikian rupa telah menjurus kepada negaranegara tersebut dilabel mewujudkan diskriminasi terhadap wanita, melanggar hak asasi manusia dan seterusnya menjadi sasaran dikecam sehingga mewujudkan Islamofobia.

Nilai berita bukan bersifat universal dan sering kali berbeza mengikut budaya. Wartawan boleh melaporkan peristiwa yang mempunyai nilai berita dalam konteks persefahaman yang dipersetujui di antara industri media dengan kerajaan dan badan-badan profesional media seperti yang terkandung dalam Kod Etika Wartawan Malaysia yang diperkenalkan oleh Institut Akhbar Malaysia (20 Mei 1989). Begitupun pada dasarnya nilainilai berita (news values) pada dasarnya adalah sama merujuk kepada nilai-nilai yang diperkenalkan oleh Galtung dan Ruge (1965) dan kemudiannya dikemaskini dan perkembangkan oleh Harcup dan O'Neil (2001) seperti negativiti, konflik, keekskusifan, minat insani, kesemasaan, relevan, dan sebagainya. Apa yang membezakannya ialah pemilihan dan keutamaan nilai-nilai yang ingin ditekankan. Sensasionalisme (sensationalism) selalu boleh dijumpai dalam kedua-dua kewartawanan di negara-negara Barat dan Islam (isu-isu yang melibatkan tanggungjawab sosial media) tidak kira milik kerajaan mahupun swasta. Di sini peranan pengampang berita penting kerana pengampangan lebih dari sekadar memilih atau menolak berita kerana ia merangkumi mengubah isi cerita dan bentuk berita, dan pengampangan tidak berakhir pada saluran berita kerana pengguna media juga bertindak sebagai pengampang kepada orang lain. Pengampangan oleh pihak akhbar sangat penting kerana akhbar harus mempunyai usaha mengesahkan fakta maklumat yang ingin disiarkan agar tidak mengelirukan (mislead) masyarakat.

Etika kewartawanan berasaskan nilai-nilai moral berperanan penting menetapkan suatu piawaian profesionalisme yang tinggi. Begitupun, etika kewartawanan yang bersifat silang budaya (Christians \& Traber, 1997) amat diperlukan dalam konteks Malaysia kerana umumnya kewartawanan yang bertanggungjawab diperlukan oleh mana-mana negara apatah lagi globalisasi menyaksikan pengaliran berita antarabangsa. Ini juga bermaksud kemungkinan suatu model kewartawanan hibrid yang mengabungkan nilai-nilai Barat, Islam dan budaya masyarakat multi-entik Malaysia. Salah satu polemik yang boleh dilihat di Malaysia adalah apabila ada akhbar-akhbar tertentu yang cuba menulis dari sudut kepentingan kaum tertentu sahaja akhirnya menjurus kepada ketegangan kaum. Salah satu contoh tipikal ialah "Apa lagi Cina mahu?" yang mana akhbar arus perdana yang sekian lama bertapak di Malaysia telah mengantungkan operasi mereka pada tahun lepas (2019). 
Limitasi kebebasan bersuara dalam akhbar sering kali bukan disebabkan oleh sekatan dan kawalan kerajaan tetapi merupakan susulan daripada penapisan kendiri yang dilakukan oleh akhbar masing-masing atas kesedaran timbul daripada etika kewartawanan. Meskipun isuisu moral bukan isu dalam politik (moral issues is none political issues), etika kewartawanan merupakan garis panduan amalan yang paling penting menjauhi diri wartawan daripada terjebak dengan salahlaku yang memperjudikan integriti kewartawanan. Begitupun, etika kewartawanan masih tetap bergantung kepada ciri-ciri yang ada pada sesebuah negara (berbanding pendekatan umum). Model McNelly (1959) telah menunjukkan pengampangan dalam proses penerbitan berita jauh lebih kompleks daripada model White (1950) dan saban tahun perbincangan ini semakin berkembang selaras dengan perkembangan tekonologi komunikasi sehinggalah muncul kewartawanan warga yang hampir merubah segala-galanya. Dewasa ini sering kali lihat akhbar mengambil (pick-up) isu-isu yang tular dalam media sosial untuk dilaporkan.

Peranan tambahan media adalah menggalakkan penyertaan rakyat dalam usaha-usaha pembangunan, memelihara dan memperkuatkan keharmonian dan perpaduan kaum dan juga toleransi beragama, memelihara hubungan bilateral baik negara Malaysia dengan negaranegara jiran serantau, memupuk taat setia rakyat kepada negara dan mempertahankan kedualatan raja-raja dan imej baik agama Islam. Sebarang bentuk provokasi mahupun pemikiran hedonisme ("melakukan apa yang dirasakan baik") dan penerbitan provokatif harus dihalang sama sekali. Ini penting terutamanya dengan peningkatan populariti kewartawanan warga di Malaysia. Apa yang dirakam dengan telefon pintar oleh saksi mahupun mangsa sering kali lebih popular daripada apa yang dilaporkan oleh media. Kapsyen yang diletakkan selalunya menjadi pembayang kepada arah tuju interpretasi khalayak.

\section{MODEL KEWARTAWANAN MALAYSIA}

Mengambilkira konteks masyarakat majmuk, model kewartawanan yang ideal untuk konteks Malaysia haruslah mengambilkira konsep pluralisme dan mencerminkan masyarakat pluralistik Malaysia dengan mengimbangi ruang media dengan sensitiviti masyarakat. Masyarakat yang berbilang kaum, kebudayaan dan agama merupakan keunikan negara Malaysia tetapi juga merupakan cabaran paling getir (stumbling block) kepada kebebasan kewartawanan di Malaysia agar tidak menganggu gugat agenda perpaduan kaum dan pembangunan negara. Isu etnik dan agama sering dimanipulasi oleh ahli-ahli politik (tindakan politik) untuk meraih sokongan undi yang mana sering berakhir dengan suasana kucar-kacir. Justeru itu apa yang dianggap sebagai inflamasi perkauman dan tidak boleh diterima dalam masyarakat yang mempraktiskan akhbar libertarian atau tanggungjawab sosial (akhbar terkawal). Pertikaian yang timbul dalam model tanggjawab sosial adalah 'polisi siapa?' ('who's policies?') melibatkan tanggungjawab kolektif semua pihak. Pentadbiran kerajaan terbahagi kepada tiga lapisan iaitu kerajaan persekutuan, kerajaan negeri dan kerajaan tempatan. Kerajaan memerintah kerana ia memperolehi mandat (dipilih oleh) daripada majoriti rakyat Malaysia.

Model akhbar klasik authoritarian Siebert et al. di mana akhbar dikawal sepenuhnya oleh kerajaan sudah pastinya tidak sesuai dengan konteks mediaskap kontemporari di Malaysia dan lebih penting ialah komitmen daripada kerajaan untuk membuka ruang yang lebih luas untuk kebebasan berakhbar. Begitu juga dengan model media Soviet kerana tidak bersesuaian dengan konteks negara Malaysia sebagai sebuah negara raja berperlembagaan dan demokrasi berparlimen. Dua model baharu yang diperkenalkan McQuail (2010) iaitu teori media pembangunan (development media theory) dan teori penyertaan-demokratik media (democratic-participant media theory) lebih sesuai mengambarkan konteks Malaysia. Penyertaan daripada semua pihak di mana individu-individu berupaya meluahkan pandangan mereka terhadap pelbagai isu berteraskan demokrasi berparlimen dan bukannya demokrasi 
yang berlain-lain makna. Pada asasnya terdapat keadaan kebebasan akhbar boleh dikawal sama ada melalui akses kepada maklumat, sekatan terhadap penerbitan maklumat (penapisan, injunksi), liabiliti kepada penerbitan (saman kefitnahan dan melanggari privasi, denda dan penjara), mahupun mengkehendaki wartawan memberi kenyataan atau mendedahkan sumber maklumat. Kerajaan boleh menggunakan alasan demi ketenteraman awam, mencegah jenayah dan memastikan objektiviti pihak berkuasa kehakiman menjalankan tanggungjawab mereka untuk campur tangan dalam urusan akhbar. Penerbitan yang mengandungi kes-kes juvana (penderaan kanak-kanak, kandungan seksual dan keganasan) serta isu-isu yang menyentuh sensitiviti perkauman juga tertakhluk kepada limitasi daripada kerajaan. Apa yang dibincangkan oleh Mellor (2005) berkenaan kerajaan dan pihak gereja (paderi) sebagai penentu atau pentafsir utama (primary definers) kandungan politik dan agama tidak sesuai untuk konteks Malaysia yang terdiri daripada masyarakat majmuk. Begitu juga dengan idea "Arab Street" yang menentang semua perkara Amerika Syarikat (kebanyakan negara-negara Arab mempunyai sejarah penapisan dan kawalan media yang bersifat authoritarian yang panjang) adalah tidak sesuai. Malaysia kini bukannya ingin melalui zaman Renaissance mahupun pergerakan Reformasi yang tercetus di Eropah mulai abad ke-16 tetapi transformasi ke arah penambahbaikan sistem kerajaan dalam suatu persekitaran yang lebih mencabar dari ketika negara-negara Eropah melaluinya disebabkan oleh globalisasi.

Umumnya dalam makalah ini melihat akhbar sebagai tunjang kepada politik, ekonomi dan sosial seperti mana digambar dalam ilustrasi gambarajah di bawah mengikut konteks kerajaan (perundangan dan peraturan):-

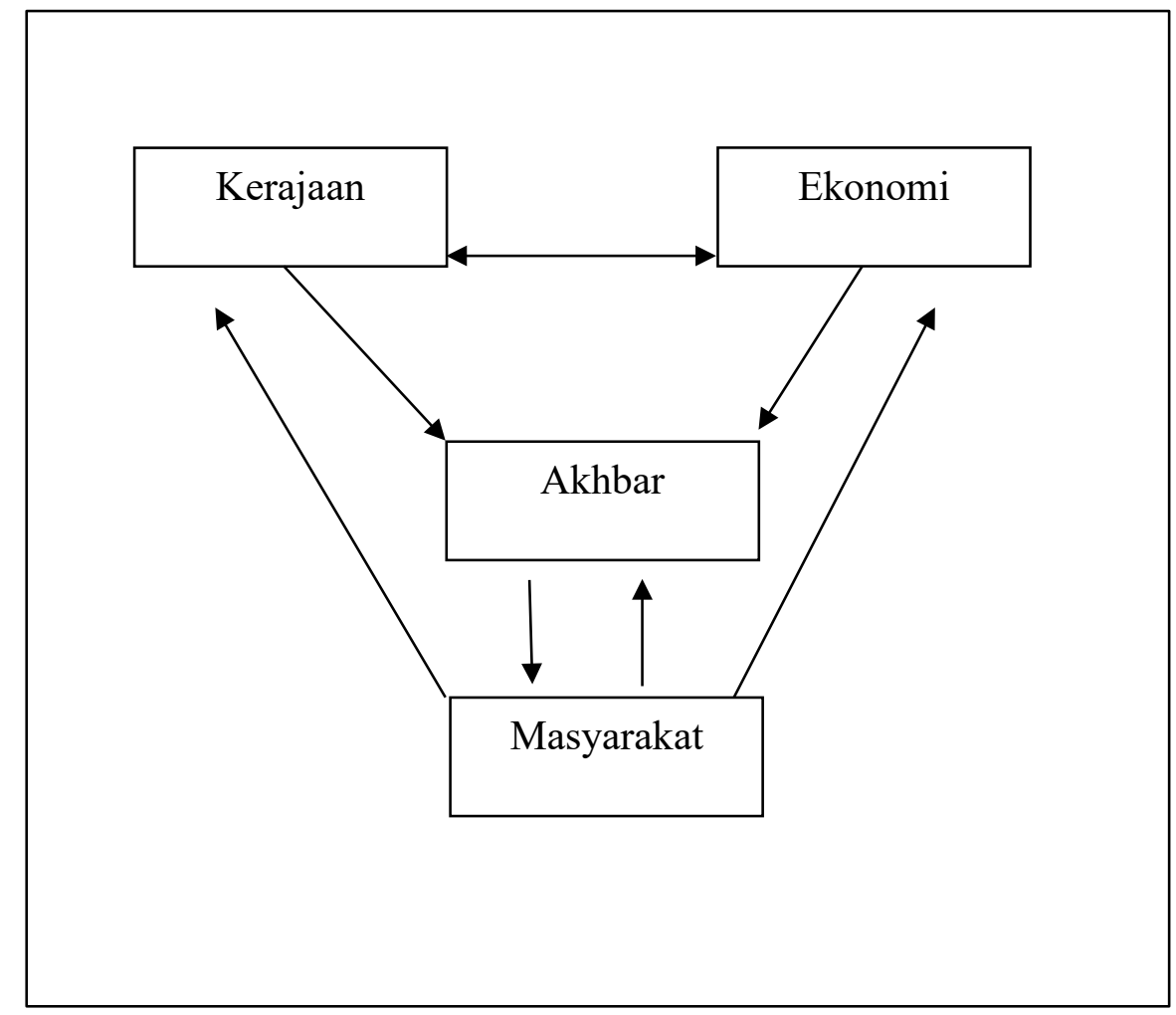

Sumber: Kajian Lee Kuok Tiung, Siti Suriani Othman, \& Liana Mat Nayan, 2012 
Kesemua pembolehubah di bawah keempat-empat kluster ini beroperasi mengikut konteks kerajaan negara masing-masing iaitu bergantung kepada jenis perundangan dan peraturan-peraturan yang ada berkenaan kebebasan operasi media. Perbezaannya hanyalah bergantung kepada cara mana kreativiti masing-masing dalam mengadaptasikan operasi media mengikut peraturan yang sedia ada mahupun bagaimana band the laws. Akhbar merupakan tunjang kepada rutin seharian masyarakat iaitu playmaker yang menentukan isu-isu semasa yang harus mereka ketahui berdasarkan penentuan agenda dan pembingkaian akhbar. Kerajaan merupakan pengubal polisi dan peraturan menentukan sejauhmana batas kebebasan berakhbar. Kelangsungan sesebuah akhbar juga bergantung kepada ekonomi penerbitan (economic of publishing) mereka sebagaimana yang dibincangkan oleh Picard (2002). Ahli-ahli mahupun parti-parti politik sering kali ingin memainkan peranan sebagai pencatur yang mengatur agenda masyarakat dan ekonomi negara tetapi kuasa mereka adalah terbatas disebabkan had komunikasi mereka di mana mereka masih bergantung kepada ruang dan masa yang diberikan oleh media tradisional kepada mereka. Meskipun mereka boleh menggunakan platform media baharu tetapi sering kali dari semasa ke semasa nampak ahli politik ditimpa kontroversi disebabkan apa yang dikongsikan dalam media sosial. Tanpa bantuan saluran-saluran media, penyampaian dan kesampaian mesej mereka terbatas dan impak advokasi mereka terhadap sesuatu isu berkenaan sektor ekonomi juga adalah terhad. Kuasa politik juga akan sentiasa cuba mempengaruhi media untuk membantu mereka memperolehi kuasa dan terus berkuasa tetapi perlu ingat media ada pengampang (gatekeeper) mereka. Di samping itu upah golongan professional untuk menguruskan imej mereka dalam media sosial mereka dengan kandungan kreatif yang sesuai. Sektor ekonomi memainkan peranan penting terhadap kelangsungan media kerana pengiklanan merupakan sumber pendapatan utama mereka. Apa-apa yang berjaya melepasi pengampangan akhbar akan disalurkan kepada masyarkat dan maklum balas (feedback) daripada mereka kepada akhbar, politik dan ekonomi itu memainkan peranan penting dalam proses kitaran tersebut. Ini sepertimana menurut Berenger (2005), media sering kali merupakan penentu agenda untuk produk budaya. Respons daripada masyarakat adalah unik disebabkan sifat heterogen mereka khususnya dipengaruhi nilai-nilai budaya dan prior knowledge yang berbeza-beza.

Objektiviti merupakan norma utama dalam kewartawanan Barat dan juga kewartawanan Islam (meskipun banyak kajian yang mendedahkan wujud subjektiviti di dalam objektiviti pelaporan berita). Pokok pangkalnya kedua-duanya menekankan fakta dan pendapat yang seimbang yang mana termasuk mengimbangi fakta-fakta dengan pendapat (balancing facts and opinions) dengan naratif yang kaya, deskripsi, dan hujah yang seimbang. Wartawan harus menggelak cerita sebelah pihak, keutamaan yang berbeza mungkin akan diberikan kepada aktor sosial yang berbeza dan kenyataan mereka. Perkembangan pendemokrasian dan kebangkitan agama mendedahkan demokrasi yang membawa makna yang berlainan kepada individu yang berlainan. Kajian pada masa depan adalah post-Enlightenment iaitu eksplorasi ilmu di luar tradisi intelektual barat.

Semua pihak juga harus lebih sensitif dengan nilai-nilai agama (religious values) dan budaya yang adakalanya dilihat tidak ditekankan dalam kewartawanan Barat baik agama Islam, Buddha, mahupun Kristian. Menghasilkan karikatur yang berunsur agama seolah-olah merupakan suatu hak kepada sesetegah akhbar Barat dan apa yang membimbangkan ialah budaya ini nampak sedang menular masuk ke masyarakat Malaysia bila ada yang melukis karikatur menghina mahupun mempersenda pemimpin-pemimpin negara yang tidak disukai mereka. Begitupun di negara-negara Barat terdapat juga Badan-badan Bukan Kerajaan (NGO) yang berpengaruh bertindak sebagai pemerhati untuk menegur tindakan mempersendakan agama secara keterlaluan. Di sini mencadangkan agar ada NGO, mahupun badan profesional bebas seperti Kesatuan Kebangsaan Wartawan Malaysia (National Union Journalist Malaysia 
- NUJM) dan Majlis Akhbar Malaysia yang memainkan peranan aktif menegur mana-mana akhbar yang bertindak di luar batas-batas tersebut.

Steele (2011) dalam masa sama turut berhujah semua pengamal media seharusnya mengamalkan sembilan elemen universal dalam kewartawanan yang baik. Sembilan prinsip kewartawanan yang baik terdiri daripada tanggungjawab untuk menyatakan kebenaran, kesetiaan kepada warganya, disiplin dalam penentusahan, mengekalkan semangat dan minda yang bebas, bertindak sebagai pemantau kuasa yang bebas, menyediakan forum bagi kritikan dan kompromi awam, mesti berusaha untuk menjadikan perkara yang penting supaya menarik dan relevan, mesti memastikan berita yang komprehensif dan mencukupi, dan mesti dibenarkan untuk menggunakan kebijaksanaan sendiri turut terkandung dalam prinsip kewartawan. Malaysia harus mengamalkan kebebasan akhbar yang bersyarat dengan ruang untuk menegur salahlaku kerajaan mahupun dalam kalangan masyarakat itu sendiri. Model yang masih dalam peringkat awal ini masih tidak lengkap daripada segi beberapa aspek khususnya pertimbangan mengambilkira pengaruh nilai berita (newsworthiness) dalam penerbitan berita, pengaruh sistem media, organisasi akhbar, budaya nasional dan tempatan terhadap produk media sesebuah negara berlainan dengan produk media dari sebuah negara lain. Tidak lupa bahawa transformasi politik tidak mampu merubah wartawan secara keseluruhannya disebabkan pengalaman lalu dan pendidikan yang diperolehi mereka.

\section{KESIMPULAN}

Umumnya apa yang dibincangkan dalam makalah ini bertujuan menangani polemik kepelbagaian dan halatuju amalan kewartawanan di Malaysia dengan meneroka sebuah model kewartawanan yang lebih ideal untuk konteks sebuah negara sekular yang unik seperti Malaysia dengan rakyatnya yang terdiri daripada masyarakat pluralistik. Model kewartawanan ini berdasarkan nilai-nilai dan prinsip-prinsip yang diperolehi daripada model kewartawanan Barat dengan prinsip kewartawanan Islam. Model kewartawanan ideal yang disarankan menekankan erti penting disesuaikan dengan realiti konteks persekitaran dan set-up semasa Malaysia khususnya mengambilkira pertimbangan meminimakan tekanan-tekanan pasaran, pihak yang berkepentingan, selain memastikan tiada mana-mana pihak dalam masyarakat pluralistik Malaysia yang dimarginalise mahupun tertindas. Ini termasuk penularan Islamofobia dalam kalangan masyarakat bukan Muslim di Malaysia disebabkan pelbagai persepsi negatif yang diperolehi mereka gara-gara pergolakan politik yang begitu bergelora di Malaysia masa kini. Sensitiviti budaya dan kebebasan berakhbar merupakan dua perkara penting yang harus wujud bersama dalam model kewartawanan ini.

\section{RUJUKAN}

Aller, E. (2007). "Vali Nasr Explains the most significant foreign policy challenge for the United State." News and Media. Diambil dari: http://fletcher.tufts.edu/news/2007/03/nasr.shtml pada 31 Ogos 2012

Ana Nadhya Abrar. (2018). Creating Successful Muslim Journalists through Journalism Ethics. Journal of Education and Social Sciences, 9(3), 15-22 retrieved from: https://www.jesoc.com/wp-content/uploads/2018/04/KC9.3_6.pdf

Berenger, R. D. (2005). "Review: The Making of Arab News by Noha Mellor." Diambil dari http://www.tbsjournal.com/ReviewMeller.html. pada 31 Ogos 2012.

Christians, C.G., \& Traber, M. (1997). Communication Ethics and Universal Values. Thousand Oaks, London: Sage Publications.

Das'ad Latif, Fauziah Ahmad, Normah Mustaffa, \& Shahrul Nazmi Sannusi. (2016). Pengaruh Objektivi Berita Tentang Tenaga Kerja Ndonesia Terhadap Imej Malaysia di Mata Masyarakat Sulawesi Selatan. Jurnal Komunikasi, 32(1), 16-46. 
Galtung, J., \& Ruge, M.H. (1965). Structure of Foreign News: Presentation of the Congo, Cuba and Cyprus Crises in Four Foreign Newspapers. Journal of Peace Research, 2(1), 6490.

Eickelman, D.F. \& Anderson, J.W. (1997). Print, Islam and the Prospects for Civic Pluralism: New Religious Writing and their Audiences. Journal of Islamic Studies, 8(1), 43-62.

Eickelman, D.F. \& Anderson, J.W. (2003). New media in the Muslim world: the emerging public sphere. Bloomington: Indiana University Press.

Elliott, C.W., \& Greer, C.F. (2010). Newsworthiness and Islam: An Analysis of Values in the Muslim Online Press. Communication Quarterly, 58(4), 414-430.

Esposito, J.L. (1992). The Islamic Threat: Myth or Reality. Oxford: Oxford University Press.

H.M. Tuah Iskandar. (1990). Kewartawanan Islam: Diabar, Tercabar, Mencabar. Kuala Lumpur: Karya Media Publisher.

Hafez, K. (Ed.). (2000). Islam and the West in the Mass Media. Fragmented Images in a Globalizing World. Cresskill, New Jersey: Hampton Press.

Hamid Mowlana. (1996). Global Communication in Transition: The end of Diversity? Thousand Oaks, CA: Sage.

Hamid Mowlana, \& Wilson, L.J. (1990). The Passing of Modernity: Communication and the Transformation of Society. London: Longman.

Hamid Mowlana. (1979). Technology versus Tradition: Communication in the Iranian Revolution. Journal of Communication, 29(3), 107-112.

Hamid Mowlana. (1989). The Islamization of Iranian Television. Intermedia, 7(5), 35-39.

Hamid Mowlana. (1993). The New Global Order and Cultural Ecology. Media, Culture \& Society, 15(1), 9-27.

Jakubowicz, A. \& Palmer, R. (2000). Framing Suharto: Media Interpretations of the Australia National Interest. Dlm. Ang, I., Chalmers, S., Law, L., \& Thomas, M. (Eds.). Alter Asian: Asian-Australia Identities in Art, Media and Popular Culture. Sydney: Pluto Press. 244-262.

Karim, H. K. 2000. Islamic peril: Media and global violence. Montreal: Black Rose Books.

Keith Johathan Deuntzer. (2009, 30 Jun). Wartawan Islam adalah pendidik, pendakwah dan pemimpin. Diambil dari https://www.mstar.com.my/lainlain/rencana/2009/06/30/wartawan-islam-adalah-pendidik-pendakwah-dan-pemimpin

Khiabany, G. 2003. Dr-Westernizing Media Theory, or Reverse Orientalism: 'Islamic Communication' as Theorized by Hamid Mowlana. Media, Culture \& Society, 25, 415422.

Lasswell, H. D. 1948. "The structure and function of communication in society." dalam Bryson, L. (penyunting). The Communication of Ideas. New York: Harper and Row.

Lazarsfeld, P. F., \& Robert K. Merton, R. K. 1948. "Mass communication, popular taste and organized social action." dalam Bryson, L. (penyunting). Communication of Ideas. New York: Harper and Row.

M. Yoserizal Saragih. (2018). Some characteristics of Islamic Journalism Based on Al Quran. Budapest International Research and Critics Institute-Journal (BIRCI-Journal), 1: 110. Retrieved from: https://bircu-journal.com/index.php/birci/article/view/1/1

Mawdudi, A.A. 1976. Human Rights in Islam. Leicester: The Islam Foundation.

McNelly, J.T. 1959. Intermediary Communicators in the International Flow of News. Journalism Quarterly, 36(1), 23-26.

McQuail, D. 1997. Accountability of Media to Society: Principles and Means. European Journal of Communication, 12(4), 511-529.

McQuail, D. 2010. Mass Communication Theory: An Introduction (6 ${ }^{\text {th }}$ Ed.). Thousand Oaks, CA, US: Sage Publications.

Mellor, N. 2005. The Making of Arab News. Lanham, MD: Rowman \& Littlefield. 
Michael B. Munnik. 2019. Answering for Islam: Journalistic and Islamic Conceptions of Authority. doi:10.3390/rel10070435

Mohammad Hashim Kamali. 1997. Freedom of Expression in Islam. Cambridge, UK: Islamic Texts Society.

Mohammad Hashim Kamali. 2000. Freedom of Expression in Islam. Kuala Lumpur: Ilmiah Publisher.

Mohammad Hashim Kamali. 2002. Freedom, Equality and Justice in Islam. Kuala Lumpur: Ilmiah Publisher.

Nerawai Sedu. (2009). An Analysis of Islamic Conceptualisations of Press Freedom in Malaysia. Tesis PhD. School of Journalism and Communication, The University of Queensland.

Nordenstreng, K. \& Topuz, H. (Ed.). (1989). Journalist: Status, Rights and Responsibilities. Prague: International Organization of Journalists.

Picard, R.G. \& Rimmer, T. (1999). Weathering a Recession: Effects of Size and Diversification on Newspaper Companies," The Journal of Media Economics, 12(1), 1-18.

Picard, R.G. (2002). The Economics and Financing old Media Companies. USA: Fordham University Press.

Sayeed Al-Seini. (1986). An Islamic Concept of News. The American Journal of Islamic Social Sciences, 3(2), 277-289.

Schramm, W., \& Roberts, D.F. (Ed.). (1971). The Process and effects of mass communication. Urbana: University of Illinois Press.

Shamsul Amri Baharuddin. (2008). Many ethnicities, many cultures, one nation: The Malaysian experience. Kertas Kajian Etnik UKM Bil. 2(November) 2008. Institut Kajian Etnik (KITA). Universiti Kebangsaan Malaysia. Bangi, Selangor.

Siebert, F.S., Peterson, T., \& Schramm, W. (1963). Four Theories of the Press. University of Illinois Press.

Skjerdal, T.S. (2008). Self-censorship among news journalists in the Ethiopian State Media. African Communication Research, 1(2), 185-206.

Skjerdal, T.S, \& Lule, H. (2009). Uneven Performances by the Private Press in Ethiopia: An Analysis of 18 Years of Press Freedom. Journal of Communication \& Language Arts, 3(1), 44-59.

Steele, J. (2011). Justice and Journalism: Islam and Journalistic Values in Indonesia and Malaysia. Journalism, 12(5), 533-549. . New social media not true journalism - US academician. (2011, July 21). Thursday. The Borneo Post. Diambil dari http://www.theborneopost.com/2011/07/21/new-socialmedia-not-true-journalism-\%E2\%80\%93-us-academician/ pada 12 September 2012.

Zulkiple Abd. Ghani. (1986). Islam, Komunikasi dan Teknologi Maklumat. Kuala Lumpur: Utusan Publications \& Distributors Sdn Bhd.

David McMohan. (2012, 14 October). If in doubt, do not post. Sunday Star. Focus. P. 25. Retrieved from: https:/www.thestar.com.my/news/nation/2012/10/14/if-in-doubt-donot-post . (2011, 20 Julai). "Media sosial baru bukan kewartawanan sebenar." diambil dari http://www.bharian.com.my/bharian/articles/2011072020131420110720201314/Artic le pada 12-7-2012.

. (2012, 21 September). Is the Muslim world ready for more cartoons?. Diambil dari http://www.civilliberty.org.uk/newsdetail.php?newsid=1558 pada 4-12-2012. 